"This is the peer reviewed version of the following article: ChemSusChem 2017, 10, 1233-1240, which has been published in final form at DOI: $10.1002 /$ cssc.201601520. This article may be used for non-commercial purposes in accordance with Wiley Terms and Conditions for Self-Archiving published at http://olabout.wiley.com/WileyCDA/Section/id-820227.html." 


\title{
Mechanistic Insights into the Carbon Dioxide-Cyclohexene Oxide Copolymerization reaction: Is one Metal Center enough?
}

\author{
Joan González-Fabra, ${ }^{\left[{ }^{[a]}\right.}$ Fernando Castro-Gómez, ${ }^{\left[{ }^{[a]}\right.}$ Arjan W. Kleij ${ }^{[a, b]}$ and Carles Bo* $[\mathrm{a}, \mathrm{c}]$
}

\begin{abstract}
A detailed study on the mechanism for the alternating copolymerization of cyclohexene oxide $(\mathrm{CHO})$ and $\mathrm{CO}_{2}$ mediated by a [Al\{amino-tri(phenolate)\}]/NBu 4 l binary catalyst system has been carried out using density functional theory (DFT) based methods. Four potential mechanisms (one monometallic and three bimetallic) were considered for the first propagation cycle of the $\mathrm{CHO} / \mathrm{CO}_{2}$ copolymerization. The obtained Gibbs free-energies provide a rational for the relative high activity of a non-covalent dimeric structure formed in situ and thus the feasibility of a bimetallic mechanism to obtain polycarbonates quantitatively. Gibbs free energies also indicate that the alternating copolymerization was favoured over the cyclic carbonate formation.
\end{abstract}

\section{Introduction}

Climate change is one of the main societal challenges that we face nowadays. Aiming to build up a more sustainable and environmentally friendly chemical industry, the use of natural resources is a main route towards the realization of this important goal. ${ }^{[1]}$ Therefore it is necessary to substitute chemical production based on crude oil, natural gas and coal by finding renewable carbon sources and improving the sustainability of chemical synthesis. One of the most interesting carbon-based alternatives to fossil sources is carbon dioxide, which constitutes the main byproduct of many chemical processes such as the combustion of organic fuels, the aerobic metabolic processes of living organisms, the decay of organic materials and the fermentation of sugars. All these chemical reactions release a significant amount of $\mathrm{CO}_{2}$ to the atmosphere, aggravating the greenhouse effect and consequently climate change.

Carbon dioxide is a renewable, non-toxic and inexpensive one-carbon building block that can be used for many synthetic applications in chemistry. ${ }^{[2]}$ However, carbon dioxide conversion is not straightforward and requires appropriate and efficient technologies for its activation and conversion because of its kinetic and thermodynamic stability. A successful approach to overcome this high stability is to react $\mathrm{CO}_{2}$ with relatively high free energy compounds, such as epoxides, in the presence of a

[a] J. González-Fabra, Dr. Fernando Castro-Gómez, Prof. Dr. A. W. Kleij, Prof. Dr. C. Bo Institute of Chemical Research of Catalonia (ICIQ), Av. Països Catalans 16, 43007 Tarragona, Spain

E-mail: cbo@iciq.cat

[b] Prof. Dr. A. W. Kleij

Catalan Institute of Research and Advanced Studies (ICREA), Pg. Lluís Companys 23, 08010 Barcelona, Spain

[c] Prof. Dr. C. Bo

Departament de Química Física i Inorgànica, Universitat Rovira i

Virgili, Marcel•lí Domingo s/n, 43007 Tarragona, Spain

Supporting information for this article is given via a link at the end of the document. suitable catalyst to gain both a thermodynamic and kinetic driving force. This successful process is interesting from an industrial point of view because it generates minimal waste, can be carried out under relatively mild temperature/pressure conditions and represents high atom economy.

From a chemo-selective point of view, this approach can lead to the formation of two commercially relevant products: cyclic carbonates $^{[3]}$ and polycarbonates (Figure 1). Cyclic carbonates are interesting products that can be used for many direct applications or as intermediates to synthesize high added-value products. ${ }^{[4]}$ Despite the massive attention for the formation of cyclic carbonates, polycarbonate synthesis has also received extensive attention as these polymers are valuable products from an industrial point of view. Aliphatic polycarbonates are biodegradable with useful properties that might become a potential alternative for conventional polymers based on phosgene.

Polycarbonates can be synthesized from dienes ${ }^{[5]}$ or epoxides $^{[6]}$ including propylene oxide ${ }^{[7]}$ or cyclohexene oxide $(\mathrm{CHO}){ }^{[8]}$ In this context, Williams et al. have made important contributions towards a better mechanistic understanding of $\mathrm{CHO} / \mathrm{CO}_{2}$ copolymerization (and related processes) catalysed by a dinuclear $\mathrm{Zn}$ complex, in which both metallic centers are involved in the reaction mechanism. ${ }^{\left[{ }^{[]}\right.}$Such bimetallic mechanisms have also been reported by other groups using most often salen-based catalyst systems. ${ }^{[10]}$ Moreover, the copolymerization (and use) of renewable oxiranes such as limonene oxide have also been studied by the groups of Coates and Kleij to obtain completely renewable polycarbonates. ${ }^{[11]}$ The latter group reported on a detailed DFT study that showed that a bimetallic catalysis pathway is energetically most favourable. ${ }^{[11 \mathrm{~b}]}$ Additionally, a number of different catalysts have been designed and applied in the copolymerization reaction of epoxides and $\mathrm{CO}_{2}$ using a large variety of metals. ${ }^{[12]}$
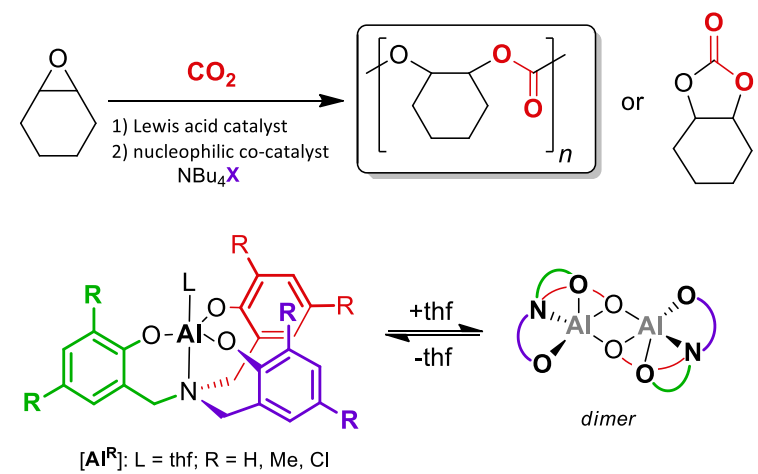

Figure 1. The reaction between $\mathrm{CHO}$ and $\mathrm{CO}_{2}$ to produce either polycarbonates or cyclic carbonates. Below, an [Al\{amino-tri(phenolate)\}] complex and its dimerization potential. 
Following our previous studies on the mechanism of both cyclic carbonate $\mathrm{e}^{[3 \mathrm{~d}-\mathrm{e}]}$ and polycarbonate $\mathrm{e}^{[11 \mathrm{~b}]}$ formation reactions, herein we report a comprehensive computational study on the mechanism for the copolymerization reaction between $\mathrm{CHO}$ and $\mathrm{CO}_{2}$ mediated by the binary catalyst system illustrated in Figure 1 composed of $\left[\mathrm{Al}^{\mathrm{Cl}}\right]$ and $\mathrm{NBu}_{4}$ l. Moreover, we have focused on the origin of the chemo-selectivity by comparing the rate of cyclic carbonate formation versus the copolymerization rate.

This reaction is mediated by the binary system that acts as a highly efficient catalytic system for $\mathrm{CO}_{2}$ /epoxide copolymerization. Three separate aspects of this $\mathrm{CHO} / \mathrm{CO}_{2}$ coupling process have been studied in detail, i.e. (i) determining the most plausible mechanism for $\mathrm{CO}_{2}$ copolymerization with epoxides, (ii) elucidating the chemo-selective nature of this process, and (iii) explore computationally catalyst modifications to improve the performance of this reaction. The results disclosed herein have further led to a mechanistic proposal that is based on the noncovalent and reversible formation of a bimetallic Al-complex. This dimeric species showed improved reactive intermediate stabilization potential resulting in a smaller energetic span of the epoxide $/ \mathrm{CO}_{2}$ copolymerization process. This attractive dimerization feature has great potential to be further developed in the area of copolymerization of $\mathrm{CO}_{2}$ and epoxide monomers.

\section{Results and Discussion}

Initiation and Carbon Dioxide Insertion. In our previous studies concerning the $\left[\mathrm{Al}^{\mathrm{Cl}}\right]$-mediated conversion of carbon dioxide and epoxides into cyclic carbonates, we proposed a reaction mechanism using DFT-based methods. ${ }^{[3 \mathrm{~d}]}$ The first mechanistic steps of the cyclic carbonate formation and the copolymerization reaction have found to be the same. Therefore, these steps related to the epoxide ring-opening process and the carbon dioxide insertion, have been depicted jointly (Scheme 1).

These first steps start with the coordination of $\mathrm{CHO}$ to the aluminium complex leading to a stable intermediate $($ IC) with a relative free-energy of $-16.5 \mathrm{kcal} \cdot \mathrm{mol}^{-1}$. After initial formation of this coordination complex IC, the nucleophilic co-catalyst $\left(\mathrm{NBu}_{4} \mathrm{I}\right)$ attacks one electrophilic carbon centre of the epoxide through a ring-opening step, which leads to a metal alkoxide (Int1), which is more stable than the previous intermediate $(I C)$ by $1.8 \mathrm{kcal} \cdot \mathrm{mol}^{-1}$. This process is the initiation step, which has to overcome a transition state (TS1) with a Gibbs free energy barrier of 7.7 $\mathrm{kcal} \cdot \mathrm{mol}^{-1}$.

After the initiation step, a $\mathrm{CO}_{2}$ molecule is inserted into the $\mathrm{Al}-\mathrm{O}$ bond forming a chelating carbonate (Int2) bonded to the $\mathrm{Al}$ center with a relative free energy of $0.8 \mathrm{kcal} \cdot \mathrm{mol}^{-1}$. This step has a relative barrier of $21.1 \mathrm{kcal} \cdot \mathrm{mol}^{-1}$, since TS2 has a relative Gibbs free energy of $2.8 \mathrm{kcal} \cdot \mathrm{mol}^{-1}$. The second part of the $\mathrm{CO}_{2}$ insertion is an isomerization process to form a linear hemi-carbonate (Int3) through a relatively high energy demanding (at $11.3 \mathrm{kcal} \cdot \mathrm{mol}^{-1}$ ) transition state (TS3). From this $\mathbf{I n t} \mathbf{3}$ intermediate $(-2.2 \mathrm{kcal} \cdot \mathrm{mol}$ ${ }^{1}$ ), different reaction pathways emerge (see Scheme 1), to produce either cyclic carbonate in which the $\mathrm{O}[2]$ atom attacks the electrophilic carbon bonded to the iodide, or propagation towards a polycarbonate product occurs.
The key step that allows for copolymerization is the nucleophilic attack of the carbonate moiety in Int3 onto a second $\mathrm{CHO}$ monomer. This process could take place directly from Int3 involving only one (Monometallic Co-Poly) or two aluminium metal centres (Bimetallic Co-Poly). Furthermore, in the case of a bimetallic mechanism, each oxygen atom of the carbonate may be involved in the attack onto the second epoxide monomer. On the other hand, an alternative dimeric species that arises from the dimerization of two individual $\mathrm{Al}$ (aminotriphenolate) complexes through two $\mu$-oxo bridges previously described by Kleij et al. ${ }^{[3 \mathrm{~d}]}$ can also be catalytically active. Hence, we have computed the Gibbs free energy profiles of all these mono- and bimetallic pathways.

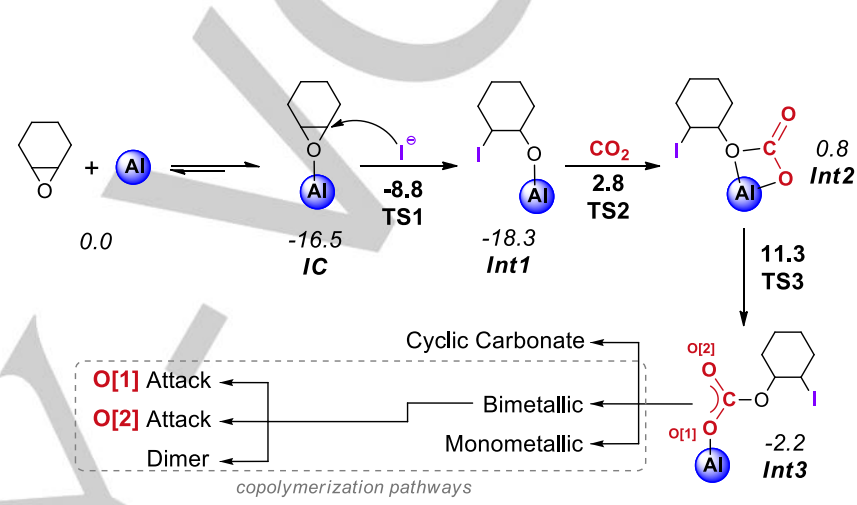

Scheme 1. Schematic representation of the initial $\mathrm{CHO}$ coordination, epoxide ring-opening, carbon dioxide insertion and isomerization steps. Calculated relative free energy values for each intermediate are presented under each structure in italics $\left(\mathrm{kcal} \cdot \mathrm{mol}^{-1}\right)$. Transition state energy values for each step are also shown (in boldface) under each reaction arrow. Al stands here for [AICl].

Ring Closing versus Propagation Cycle. In Figure 2, we present the free energy profiles for all studied reaction pathways, and in Figure 3 the bimetallic and the dimeric copolymerization reaction mechanisms are compared in detail. As we explained above, the reaction pathway related to the formation of the cyclic carbonate (purple) starts with the nucleophilic attack of $\mathrm{O}[2]$ to the electrophilic carbon centre bonded to the iodide. This step has to overcome a relative barrier of $11.0 \mathrm{kcal} \cdot \mathrm{mol}^{-1}$ associated to the difference between Int3 $\left(-2.2 \mathrm{kcal} \cdot \mathrm{mol}^{-1}\right)$ and TS-cc $(8.8 \mathrm{kcal} \cdot \mathrm{mol}$ $\left.{ }^{1}\right)$. Hereafter, a stable intermediate designated $\boldsymbol{C} \boldsymbol{C}$ is formed $\left(-11.0 \mathrm{kcal} \cdot \mathrm{mol}^{-1}\right)$, which has the cyclic carbonate product still bonded to the Al-complex through O[1]. Finally, the cyclic carbonate is released and a new $\mathrm{CHO}$ molecule coordinates to the aluminium. This final step has a relative free energy of -16.5 $\mathrm{kcal} \cdot \mathrm{mol}^{-1}$, which is effectively the Gibbs free energy of the formation of the cyclic carbonate $\left(\Delta G_{r}\right)$.

Int3 is the starting point for the propagation cycle relevant for the copolymerization process, so we considered the four different mechanisms outlined in Scheme 1. The least favorable one is the monometallic mechanism (red profile in Figure 2) that has to overcome an absolute barrier of $46.8 \mathrm{kcal} \cdot \mathrm{mol}^{-1}$. This mechanism starts with the coordination of $\mathrm{CHO}$ to a penta-coordinated $\mathrm{A}$ species $(\boldsymbol{I C}-\boldsymbol{p})$ occupying an equatorial coordination site leading 


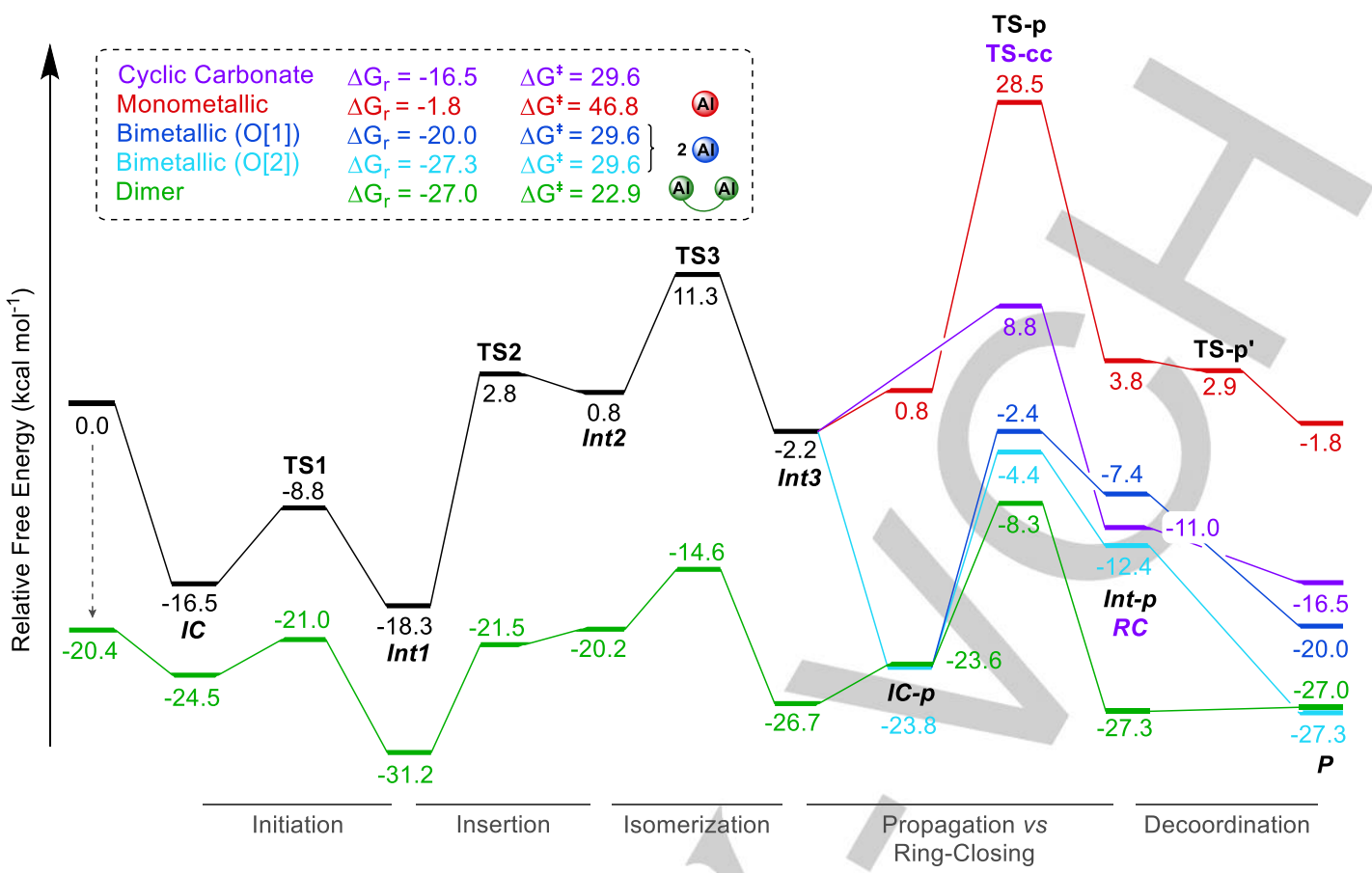

Figure 2. Free-energy profiles for the four copolymerization mechanisms and the cyclic carbonate formation (purple trace). The copolymerization reaction mediated by one [A $\left.\right|^{\mathbf{C l}^{\prime}}$-complex is depicted in red after Int 3 . The dark and light blue traces refer to the free energy changes related to the propagation steps for the different bimetallic mechanisms with $\mathrm{O}[1]$ and $\mathrm{O}[2]$ acting as nucleophilic centres. The green profile represents the energy profile for the dimeric [Al' $]$-catalyst.

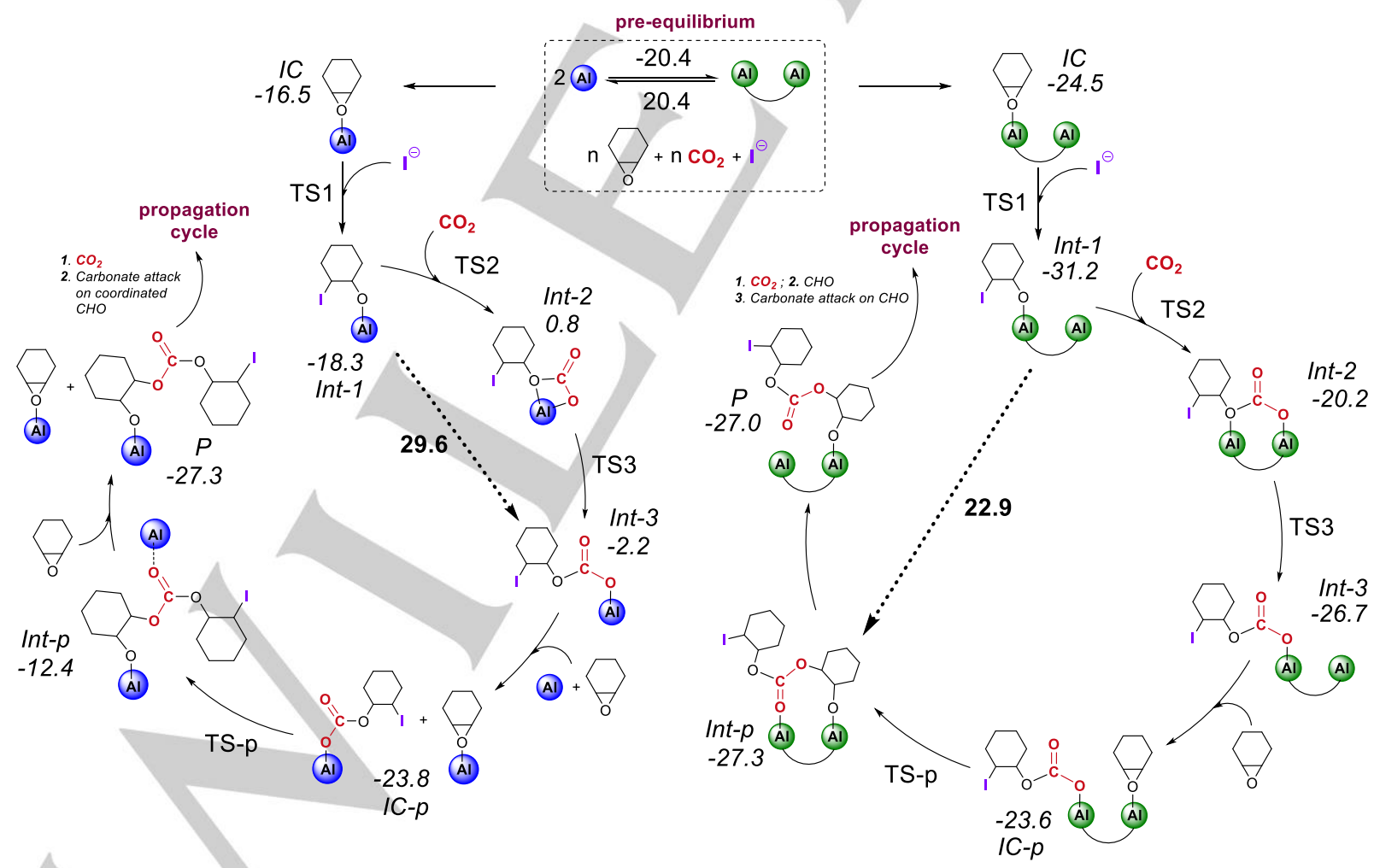

Figure 3. Catalytic cycles showing the energy profiles for the bimetallic and dimer-mediated copolymerization pathways up to second propagation step. The relative free energies $\left(\mathrm{kcal} \cdot \mathrm{mol}^{-1}\right)$ of the intermediates are shown in italics beside each structure. The energetic span of both the bimetallic (O[2] attack) and dimer-mediated pathway is shown in boldface. The formation energy of the dimer is shown at the top. 


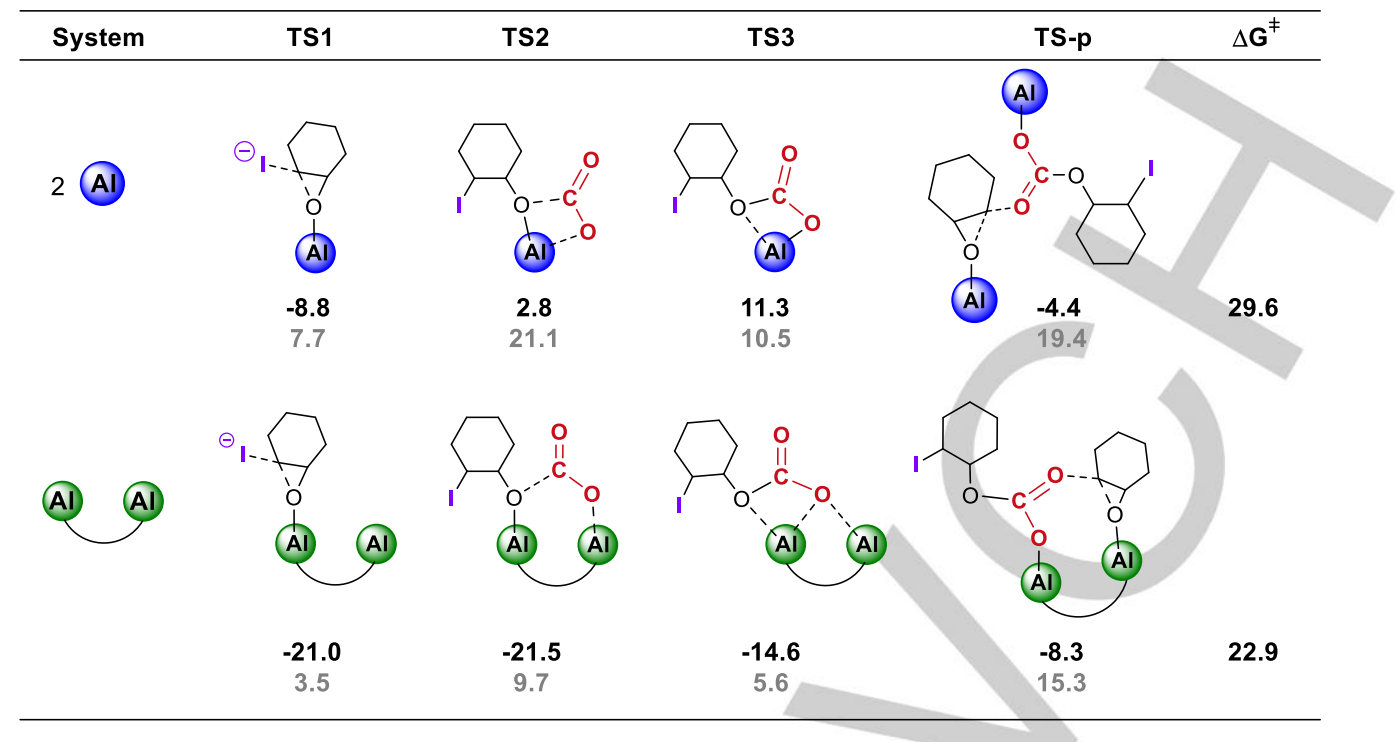

Figure 4. Schematic representation of the transition states for the bimetallic mechanism $(\mathrm{O}[2]$ attack) and the dimer-mediated pathway. The relative freeenergies $\left(\mathrm{kcal} \cdot \mathrm{mol}^{-1}\right)$ are given in boldface (black color), and the relative barrier (in grey-scale) was calculated as the free energy difference between the respective $\mathbf{T S}$ and the previous intermediate for each step.

to an octahedral structure with a relative energy of $0.8 \mathrm{kcal} \cdot \mathrm{mol}^{-1}$. Subsequently, the coordinated linear carbonate attacks the $\mathrm{CHO}$ through a transition state (TS-p), with a relative barrier of 27.7 $\mathrm{kcal} \cdot \mathrm{mol}^{-1}$ with respect to the intermediate $\boldsymbol{I C}$ - $\boldsymbol{p}$. Once passing through TS-p, the obtained alkoxide coordinated to the equatorial position of the catalyst (Int-p) has a relative free-energy of 3.8 $\mathrm{kcal} \cdot \mathrm{mol}^{-1}$. The next step is a barrierless and exergonic isomerization through TS-p' $\left(2.9 \mathrm{kcal} \cdot \mathrm{mol}^{-1}\right)$ to obtain an alkoxide coordinated to the axial position of the Al-complex $(-1.8 \mathrm{kcal} \cdot \mathrm{mol}$ $\left.{ }^{1}\right)$ that can continue propagation towards a polycarbonate by alternating $\mathrm{CHO} / \mathrm{CO}_{2}$ insertions.

Alternatively, the second $\mathrm{CHO}$ monomer could stay coordinated to an Al-complex, as in IC, instead of entering the copolymerization reaction by intramolecular coupling. This would then imply the need for two aluminum complexes to be involved, one in the form of $\boldsymbol{I C}$, which activates a second $\mathrm{CHO}$ molecule, and the other stabilizing the growing chain. This combination of events is pertinent to a bimetallic mechanism. The first step of each bimetallic mechanism is the formation of a stable ensemble between $\boldsymbol{I n t} \mathbf{3}$ and $\boldsymbol{I C}$, which has a relative low free-energy $(-23.8$ $\left.\mathrm{kcal} \cdot \mathrm{mol}^{-1}\right)$. Once this ensemble is formed, both carbonate oxygen atoms $(\mathrm{O}[1]$ and $\mathrm{O}[2]$, Figure 1) can ring-open the $\mathrm{CHO}$ monomer coordinating to the Al-complex. In case of $\mathrm{O}[1]$ attack, the TS-p is $2.0 \mathrm{kcal} \cdot \mathrm{mol}^{-1}$ higher in energy (at $-2.4 \mathrm{kcal} \cdot \mathrm{mol}^{-1}$ ) than the transition state obtained $\mathrm{O}[2]$ attack (at $-4.4 \mathrm{kcal} \cdot \mathrm{mol}^{-1}$ ). After this, a new alkoxide species is formed (Int-p) having a relative free energy of $-7.4 \mathrm{kcal} \cdot \mathrm{mol}^{-1}$ and $-12.4 \mathrm{kcal} \cdot \mathrm{mol}^{-1}$ for the attack by $\mathrm{O}[1]$ and $\mathrm{O}[2]$, respectively.

The origin of the difference in stability between the nucleophilic attack through $\mathrm{O}[1]$ and $\mathrm{O}[2]$ relies in the larger steric hindrance generated by the ligands of the Al-complexes in the pathway through $\mathrm{O}[1]$ attack. The decoordination of the Alcomplex is a barrierless process that gives rise to an alkoxide bonded to a single Al-complex, $\boldsymbol{P}$ in Figure 2, and enables continuation of the propagation cycle by insertion of a new $\mathrm{CO}_{2}$ molecule forming a carbonate-ligated Al-complex which then attacks as a nucleophilic species onto an activated $\mathrm{CHO}$ coordinating a second Al-complex. The difference in stability between the $\boldsymbol{P}$ intermediates of the two bimetallic pathways becomes even larger compared to the energy difference observed for Int-p since the free energy associated to $\boldsymbol{P}$ for the $\mathrm{O}[2]$ pathway is $7.3 \mathrm{kcal} \cdot \mathrm{mol}^{-1}$ lower than that calculated for $\mathrm{O}[1]$

In addition to these bimetallic pathways, there is yet another mechanistic description available to describe the $\mathrm{CHO} / \mathrm{CO}_{2}$ copolymerization process. This alternative is made feasible as a result of the potential formation of a non-covalent dimeric Alcomplex (Figure 1). This dimerization process occurs in situ and has been previously experimentally studied for $\mathrm{Al}$ - and related $\mathrm{Fe}$ complexes having different peripheral substituents (Figure 1, $R=$ $\mathrm{H}$, Me and $\mathrm{Cl}) .{ }^{\left[{ }^{[3,13]}\right.}$ The dimerization process was calculated to be an exergonic process by $-20.4 \mathrm{kcal} \cdot \mathrm{mol}^{-1}$ (Figure 3) thus providing high stabilization with respect to two monomeric Alcomplexes. Therefore, the energy reference of the dimeric profile is $20.4 \mathrm{kcal} \cdot \mathrm{mol}^{-1}$ lower than the zero set for the previous profiles. The spontaneous though reversible formation of this dimer can be a huge advantage in new catalyst design if it allows for an energetically more favourable copolymerization pathway. Therefore, we also computed the free energy profile of this latter pathway represented in green (Figure 2). The basic steps for this dimer-mediated pathway look very similar to those presented above for the bimetallic mechanism. First, a $\mathrm{CHO}$ molecule is bonded to the axial position of one of the two aluminum centers of the dimer forming an $\boldsymbol{I C}$ intermediate with a relative free energy of $-24.5 \mathrm{kcal} \cdot \mathrm{mol}^{-1}$. The epoxide ring-opening step is also similar represented by TS1 and has a low relative barrier of $3.5 \mathrm{kcal} \cdot \mathrm{mol}$ 1. The structure of TS1 evolves into Int1, which is the most stable intermediate (at $-31.2 \mathrm{kcal} \cdot \mathrm{mol}^{-1}$ ) of the entire reaction pathway. Once this alkoxide is generated, the $\mathrm{CO}_{2}$ insertion takes place 
through TS2 having a relative free energy of $-21.5 \mathrm{kcal} \cdot \mathrm{mol}^{-1}$ with a relative barrier of $9.7 \mathrm{kcal} \cdot \mathrm{mol}^{-1}$. This barrier for the $\mathrm{CO}_{2}$ insertion step is $11.4 \mathrm{kcal} \cdot \mathrm{mol}^{-1}$ lower than that computed in the bimetallic mechanism (black trace in Figure 2). Hence, the insertion process seems to be much faster when considering the non-covalent dimer.

The next intermediate formed in the energy profile of the dimeric catalyst is a chelated carbonate, whose structure shows a slight structural difference with those of the other mechanisms. In these latter cases, the chelated carbonate that forms comprises two Al-O bonds involving the same Al center. However, in the dimer-mediated mechanism Int2 has one oxygen atom bonded to each Al center (Int2 in Figure 3). After Int2, an isomerization process takes place with a relative free-energy (TS3) of -14.6 $\mathrm{kcal} \cdot \mathrm{mol}^{-1}$ resulting in linear hemi-carbonate species (Int3) with a free energy of $-26.7 \mathrm{kcal} \cdot \mathrm{mol}^{-1}$. The coordination of a new $\mathrm{CHO}$ monomer to the free $\mathrm{Al}$ center is endergonic (IC-p at -23.6 $\mathrm{kcal} \cdot \mathrm{mol}^{-1}$ ) with respect to Int3. This pre-organization then allows for the carbonate to attack the coordinated $\mathrm{CHO}$ unit through transition state TS-p related to propagation step of the process (TS-p, see Figure 5) which is the rate-determining step in this mechanism with a barrier located at $-8.3 \mathrm{kcal} \cdot \mathrm{mol}^{-1}$. The intermediate formed after TS-p (Int-p) has a relative free energy of $-27.3 \mathrm{kcal} \cdot \mathrm{mol}^{-1}$.

Afterward, the alkoxide $\left(\boldsymbol{P}\right.$ : at $\left.-27.0 \mathrm{kcal} \cdot \mathrm{mol}^{-1}\right)$ is finally generated and the propagation cycle can continue through repeating $\mathrm{CO}_{2}$ insertion, the coordination of a new $\mathrm{CHO}$ monomer to the other $\mathrm{Al}$ center and attack of the linear carbonate onto the activated $\mathrm{CHO}$ monomer.

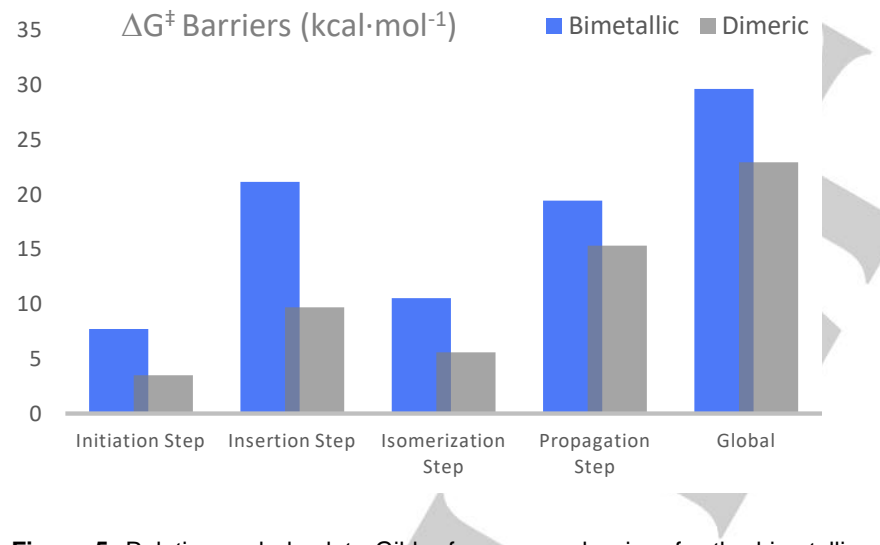

Figure 5. Relative and absolute Gibbs free-energy barriers for the bimetallic (blue) and dimer-mediated (grey) mechanisms, energies are in $\mathrm{kcal} \cdot \mathrm{mol}^{-1}$.

The lowest absolute barrier is found in the dimeric mechanism with a value of $22.9 \mathrm{kcal} \cdot \mathrm{mol}^{-1}$, and the only mechanism that seems unlikely is the monometallic one since the absolute barrier is too high $\left(46.8 \mathrm{kcal} \cdot \mathrm{mol}^{-1}\right)$. The key transition states, their relative energies and relative barriers with respect to the preceding intermediates are collected in Figure 4 for both the bimetallic (O[2] pathway) and the dimer-mediated copolymerization mechanisms. These mechanisms appear to be very similar, but the dimer-mediated pathway shows significantly lower relative barriers (Figure 5). The absolute barrier up to formation of the intermediate $\mathbf{P}$ that is the starting point for further propagation by insertion of a second molecule of $\mathrm{CO}_{2}$, is 6.7 $\mathrm{kcal} \cdot \mathrm{mol}^{-1}$ lower and thus the copolymerization catalysed by the dimeric Al-complex is favoured over the bimetallic pathway.
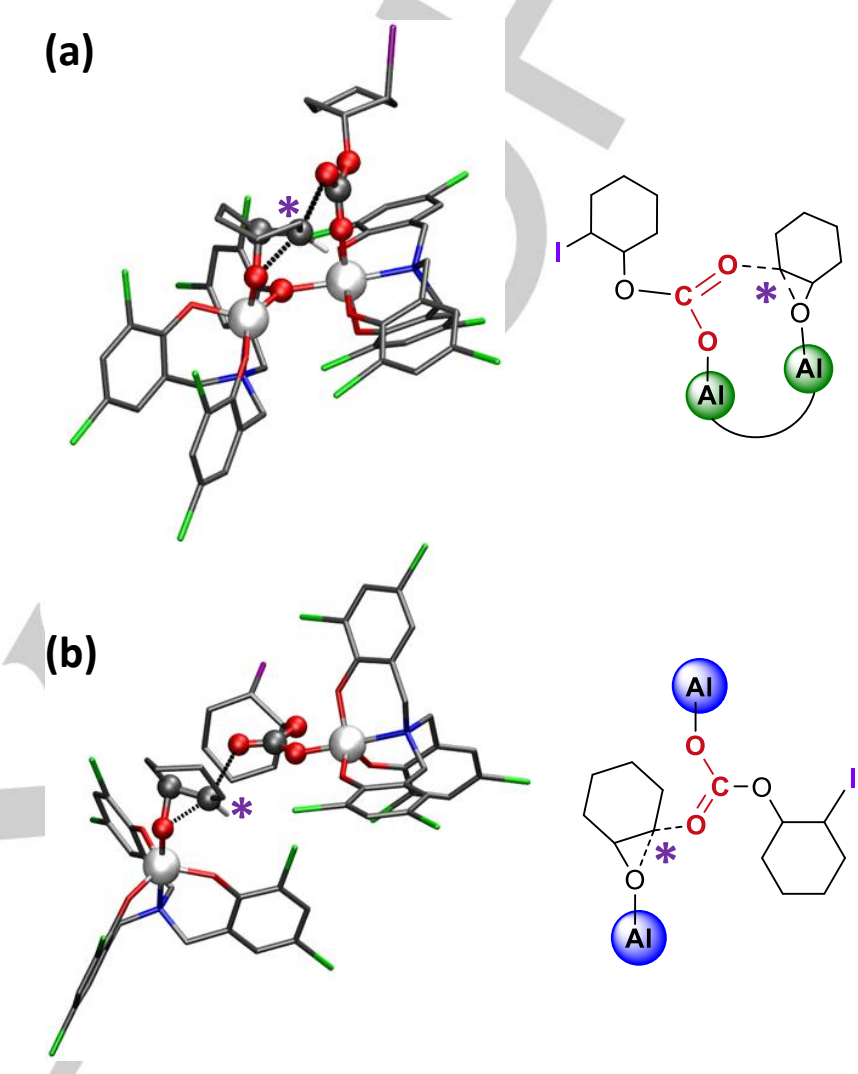

Figure 6. Optimized transition states structures related to the propagation step (TS-p) for the (a) dimer-mediated (top) and (b) the bimetallic pathways (below) together with schematic representations. The asterisks denote the carbon center of the $\mathrm{CHO}$ unit being attacked by the carbonate species produced initially.

In silico tuning of the catalytic activity. After having determined that the dimeric species enables the copolymerization of $\mathrm{CHO}$ and $\mathrm{CO}_{2}$ most efficiently, we further explored the effect of variations in the structure of the binary catalytic system. Our efforts focused on two variables: the peripheral substituents of the aminotriphenolate ligand scaffold and the type of halide used as nucleophilic agent. We chose different aromatic substituents and nucleophiles which were used before by Kleij et al. [3d, 12d, 13] including the ones mentioned in Figure $1(\mathrm{R}=\mathrm{H}, \mathrm{Me}$ and $\mathrm{Cl})$ and comparing iodide and chloride as halides. The obtained reaction free energy profiles are collected in Figure 7, in which the results for the system already calculated $\left(\left[\mathrm{Al}^{\mathrm{C}}\right] / \mathrm{NBu}_{4} \mathbf{l}\right)$ are shown in dark green, the reference profile. Note that the results for the reference profile in Figure 7 are different from the results presented in Figure 2 since for these calculations solvent effects were included during geometry optimization of the structures. 

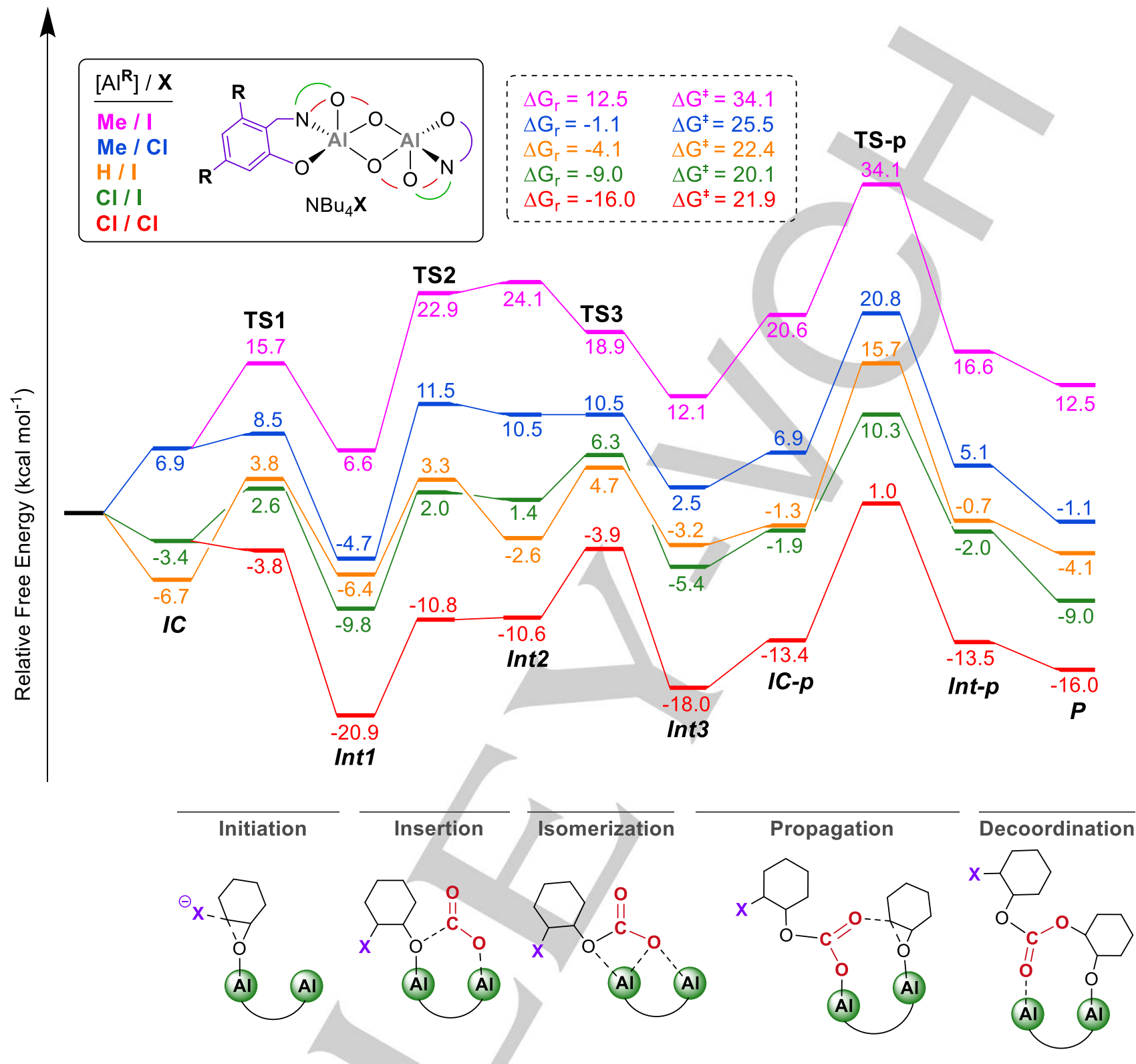

Figure 7. Free energy profiles for the copolymerization reaction of $\mathrm{CHO}$ and $\mathrm{CO}_{2}$ catalyzed by binary catalysts derived from $\left[\mathbf{A l}^{\mathbf{R}}\right]$ and either using NBu4 $\mathbf{C l}_{\text {lor }} \mathrm{NBu}_{4} \mathbf{I}$ as nucleophilic additive. Schematic representations of the TS structures related to all steps of the mechanism are shown below.

The highest free-energy profile depicted in purple corresponds to the pathway using a [Al $\left.{ }^{\mathrm{Me}}\right] / \mathrm{NBu}_{4} \mathbf{I}$ binary catalyst, where both the most stable intermediate (Int1) and the highest transition state structures (TS-p) are similar to those computed for the reference profile. The copolymerization pathway mediated by $\left[\mathbf{A l}{ }^{\mathrm{Me}}\right] / \mathrm{NBu}_{4} \mathrm{I}$ is endergonic by $12.5 \mathrm{kcal} \cdot \mathrm{mol}^{-1}$ (non-spontaneous) and the absolute barrier of this pathway is the highest observed (34.1 $\mathrm{kcal} \cdot \mathrm{mol}^{-1}$ ) being $14.0 \mathrm{kcal} \cdot \mathrm{mol}^{-1}$ higher than observed for the binary system $\left[\mathrm{Al}^{\mathrm{Cl}}\right] / \mathrm{NBu}_{4} \mathrm{I}\left(20.1 \mathrm{kcal} \cdot \mathrm{mol}^{-1}\right)$. This means that the catalyst $\left[\mathrm{Al}^{\mathrm{Me}}\right] / \mathrm{NBu}_{4} \mathrm{I}$ is the least efficient among the five considered binary systems.

For the binary system composed of $\left[\mathrm{Al}^{\mathrm{Me}}\right] / \mathrm{NBu}_{4} \mathrm{Cl}$ similar trends are observed but with lower relative free energies for the intermediates. The absolute barrier compared to the reference system $\left[\mathrm{Al}^{\mathrm{Cl}}\right] / \mathrm{NBu}_{4} \mathrm{I}$ is moderately higher by $5.4 \mathrm{kcal} \cdot \mathrm{mol}^{-1}$, but much lower than for the $\left[\mathrm{Al}^{\mathrm{Me}}\right] / \mathrm{NBu}_{4} \mathbf{I}$ catalyst (25.5 versus 34.1 $\left.\mathrm{kcal} \cdot \mathrm{mol}^{-1}\right)$. The reaction free energy also decreases with respect to the $\left[\mathrm{Al}^{\mathrm{Me}}\right] / \mathrm{NBu}_{4} \mathrm{l}$ by $13.6 \mathrm{kcal} \cdot \mathrm{mol}^{-1}$ but higher than noted for the reference catalyst by $7.9 \mathrm{kcal} \cdot \mathrm{mol}^{-1}$. Hence, the presence of electron-donating methyl groups in the $\mathrm{Al}-$ complex $\left[\mathbf{A l}^{\mathbf{R}}\right]$ seems to lower the copolymerization efficiency of the binary catalyst. Replacing the Me-groups for hydrogen atoms (i.e., $\left[\mathbf{A l}^{\mathrm{H}}\right]$ ) maintaining iodide as nucleophile $\left(\mathrm{NBu}_{4} \mathrm{I}\right)$ gives a binary system with slightly higher absolute barrier $\left(2.3 \mathrm{kcal} \cdot \mathrm{mol}^{-1}\right.$ lower) and with a reaction free-energy $4.9 \mathrm{kcal} \cdot \mathrm{mol}^{-1}$ higher than computed for the reference system $\left[\mathrm{Al}^{\mathrm{Cl}}\right] / \mathrm{NBu}_{4} \mathbf{l}$. 
The $\left[\mathrm{Al}^{\mathrm{Cl}}\right] / \mathrm{NBu} 4 \mathrm{Cl}$ catalyst system shows the lowest relative energy values, which suggests that it should be the most efficient binary combination. However, the absolute barrier is slightly higher than the reference system by $1.8 \mathrm{kcal} \cdot \mathrm{mol}^{-1}$ but on the other hand the reaction free-energy (at $-16.0 \mathrm{kcal} \cdot \mathrm{mol}^{-1}$ ) is 7.0 $\mathrm{kcal} \cdot \mathrm{mol}^{-1}$ lower. Hence, while the kinetic resistance observed for the catalyst $\left[\mathrm{Al}^{\mathrm{Cl}}\right] / \mathrm{NBu}_{4} \mathrm{Cl}$ is comparable, the thermodynamic driving force is more significant, making this combination of $\mathrm{Al}$ complex and onium salt the most efficient binary catalyst for $\mathrm{CHO} / \mathrm{CO}_{2}$ copolymerization among the series computationally investigated.

Electron-withdrawing groups in the aminotriphenolate ligand $\left(A I^{R}: R=C l\right)$ increase the Lewis acidity of the Al-complex and the potential to activate the epoxide. On the other hand, when using nucleophiles with poorer leaving group ability, the stability of the formed carbonate species $(\boldsymbol{I C}-\boldsymbol{p})$ increases thereby enhancing the probability of attack onto a coordinated $\mathrm{CHO}$ monomer at a second Al center, and the stability of the resultant alkoxide. The use of a chloride based nucleophile also decreases the probability of cyclic carbonate formation. The intramolecular back-biting of the carbonate group onto the alkyl-halide is suppressed in line with the general excellent chemo-selectivity towards the copolymer observed in the presence of $\mathrm{Cl}$-based additives.

\section{Conclusions}

In this study we have theoretically analyzed several possible reaction mechanisms for the copolymerization reaction of $\mathrm{CHO}$ and $\mathrm{CO}_{2}$, mediated by binary $\left[\mathrm{Al}^{\mathrm{R}}\right] / \mathrm{NBu}_{4} \mathrm{X}$ catalyst systems. The mechanism involving a dimeric $\left[\mathbf{A l}^{\mathbf{R}}\right]_{2}$ species that is able to form in situ in the reaction media, was found to give the most efficient copolymerization route among all the mono-metallic and bimetallic mechanistic manifolds. This complex represents the first non-covalently assembled bimetallic complex for the copolymerization reaction between epoxides and carbon dioxide. This dimeric complex facilitates the formation of an initial carbonate complex through relative low energetic barriers and faster overall reaction rates compared to various other bimetallic scenarios. The computed mechanism involving this dimer species is compatible with the chemoselectivity of the process towards polycarbonate, since this manifold is kinetically and thermodynamically favored over the cyclic carbonate pathway.

The effects of the substituents in the ligand and of the nucleophile on the catalytic activity were analysed in silico and show that the efficiency of the binary catalyst $\left[\mathbf{A l}^{\mathbf{R}}\right] / \mathrm{NBu}_{4} \mathrm{X}$ can be fine-tuned by the peripheral substituents of the ligand and the type of nucleophile, as long as the intermediate carbonate species (cf., $I \boldsymbol{C}-\boldsymbol{p})$ is not too high in energy and the energetic span of the process enables the propagation cycle. Complexes such as $\left[\mathbf{A l}^{\mathbf{R}}\right]$ with built-in dimerization potential may give access to new types of efficient epoxide/ $\mathrm{CO}_{2}$ copolymerization catalysts, and studies along this line are part of our ongoing activities.

\section{Computational Details}

All calculations in this study were performed by using the Gaussian 09 package. ${ }^{[14]}$ The B97-D3 dispersion-corrected functional ${ }^{[15]}$ was employed The standard $6-311 \mathrm{G}(\mathrm{d}, \mathrm{p})$ basis set ${ }^{[16]}$ was used to describe the $\mathrm{H}, \mathrm{C}, \mathrm{N}$ and $O$ atoms. The LANL2DZ ${ }^{[17]}$ basis sets and associated relativistic effective core pseudopotential were used for $\mathrm{Al}, \mathrm{Cl}$, and I atoms. Full geometry optimizations were performed without constrains. The nature of the encountered stationary points was characterized either as minima or transition states by means of harmonic vibrational frequencies analysis. Gibbs free energies were calculated at standard conditions ( $T=298.15 \mathrm{~K}$, $\mathrm{P}=1 \mathrm{~atm})$.

Solvent effects were accounted for the gas-phase optimized structures by using the polarizable continuum model (PCM). Solvent effects in the "In silico tuning of the catalytic activity" part, have been included during the optimization of the structures using the PCM model also. The dielectric constant $(\varepsilon)$ of the polarizable medium was set to the value reported for the simplest epoxide, ethylene oxide $(\varepsilon=12.42),{ }^{[18]}$ as the reaction takes place in epoxide rich phase. Parameters for 1-hexanol were used for this purpose $(\varepsilon=12.51)$, as implemented in the Gaussian09 package. A data set collection of computational results is available in the ioChem-BD repository ${ }^{[19]}$ and can be accessed via http://dx.doi.org/10.19061/iochembd-1-17.

\section{Acknowledgements}

We thank the ICIQ Foundation, ICREA, Generalitat de Catalunya (2014SGR409) and the Spanish Ministerio de Economía y Competitividad (MINECO) through projects CTQ2014-52824-R and CTQ-2014-60419-R, and the Severo Ochoa Excellence Accreditation 2014-2018 (SEV-2013-0319).

Keywords: carbon dioxide $\cdot$ copolymerization $\cdot$ cyclohexene oxide $\cdot$ DFT analysis $\cdot$ homogeneous catalysis

[1] (a) Walther, G.; Post, E; Convey, P; Menzel, A; Parmesan, C; Beebee T. J. C.; Fromenting, J.; Hoegh-Guldberg, O; Bairlein, F. Nature 2002 416, 389. (b) Parmesan, C.; Yohe, G. Nature 2003, 421, 37.

[2] (a) Carbon Dioxide as Chemical Feedstock, M. Aresta (ed), Wiley-VCH Weinheim 2010. (b) Sheldon, R. A. Green Chem. 2014, 16, 950. (c) Cokoja, M.; Bruckmeier, C.; Rieger, B.; Herrmann, W. A.; Kühn, F. E. Angew. Chem. Int. Ed. 2011, 50, 8510. (d) Kielland, N.; Whiteoak, C. J.; Kleij, A. W. Adv. Synth. Catal.2013, 355, 2115. (e) Mikkelsen, M.; Jørgensen, M.; Krebs, F. C. Energy Environ. Sci. 2010, 3, 43. (f) Aresta, M.; Dibenedetto, A.; Angelini, A. Chem. Rev. 2014, 114, 1709. (g) Tsuji, Y.; Fujihara, T. Chem. Commun. 2012, 48, 9956. (h) Maeda, H.; Miyazaki, Y.; Ema, T. Catal. Sci. Technol. 2014, 4, 1482. (i) Dibenedetto, A.; Angelini, A; Stufano, P. J. Chem. Technol. Biotechnol. 2014, 89, 334. (j) Liu, Q.; Wu, L.; Jackstell, R.; Beller, M. Nat. Commun.2015, 6, 5933. (k) Otto, A.;Grube, T.;Schiebahn, S.; Stolten, D. Energy Environ. Sci.2015, 8, 3283 .

[3] (a) Beattie, C.; North, M. Chem. Eur. J. 2014, 20, 8182. (b) Decortes, A.; Castilla, A. M.; Kleij, A. W. Angew. Chem. Int. Ed. 2010, 49, 9822. (c) Martínez, J. Castro-Osma, J. A.; Earlam, A.; Alonso-Moreno, C.; Otero, A.; Lara-Sánchez, A; North, M.; Rodríguez-Diéguez, A. Chem. Eur. J. 2015, 21, 9850. (d) Whiteoak, C. J.; Kielland, N.; Laserna, V.; CastroGómez, F.; Martin, E.; Escudero-Adán, Bo, C.; E. C.; Kleij, A. W. Chem. Eur. J. 2014, 20, 2264. (e) Castro-Gómez, F.; Salassa, G.; Kleij, A. W.; Bo, C. Chem. Eur. J. 2013, 19, 6289. (f) Ema, T.; Miyazaki, Y.; Shimonishi, J.; Maeda, C.; Hasegawa, J. J. Am. Chem. Soc. 2014, 136, 15270. (g) Comerford, J. W.; Ingram, I. D. V.; North, M.; Wu, X. Green Chem. 2015, 17, 1966

[4] Guo, W.; González-Fabra, J; Bandeira, N.; Bo, C.; Kleij, A. W. Angew. Chem. Int. Ed. 2015, 54, 11686. 
[5] (a) Fiorani, G.; Kleij, A. W. Angew. Chem. Int. Ed. 2014, 53, 7402. (b) Nakano, R.; Ito, S.; Nozaki, K. Nature Chem. 2015, 6, 325.

[6] (a) Inoue, S.; Koinuma, H.; Tsuruta, T. J. Polym. Sci., Part B: Polym. Lett. 1969, 7, 287. (b) Zheng, H.; Lin, X.; Chin, S.; Grinstaff, M. W. J. Am. Chem. Soc. 2015, 137, 12660. (c) Paul, S.; Zhu, Y.; Romain, C.; Brooks R.; Saini, P. K.; Williams, C. K. Chem. Commun. 2015, 51, 6459. (d) Li, T.; Hong, J.; Wei, R.; Zhang, Y.; Tong, Z.; Zhang, X.; Du, B.; Xu, J.; Fan, Z. Chem. Sci. 2015, 6, 1530. (e) Childers, M. I.; Longo, J. M.; Van Zee, N. J.; LaPointe, A. M.; Coates, G. W. Chem. Rev. 2014, 114, 8129. (f) Nakano, K.; Kobayashi, K.; Ohkawara, T.; Imoto, H.; Nozaki, K. J. Am. Chem. Soc. 2013, 135, 8456.

[7] (a) Sheng, X.; Wu, W.; Qin, Y.; Wang, X.; Wang, F. Polym. Chem. 2015, 6, 4719. (b) Cohen, C. T.; Chu, T.; Coates, G. W. J. Am. Chem. Soc 2005, 127, 10869. (c) Hatazawa, M.; Nakabayashi, K.; Ohkoshi, S.; Nozaki, K. Chem. Eur. J. 2016, 22, 13677. (d) Ohkawara, T.; Suzuki, K.; Nakano, K.; Mori, S.; Nozaki, K. J. Am. Chem. Soc. 2014, 136, 10728.

[8] For some reviews: a) D. J. Darensbourg, Chem. Rev. 2007, 107, 2388; b) G. W. Coates, D. R. Moore, Angew. Chem. Int. Ed. 2004, 43, 6618; c) M. R. Kember, A. Buchard, C. K. Williams, Chem. Commun. 2011, 47 141 ; d) S. Klaus, M. W. Lehenmeier, C. E. Anderson, B. Rieger, Coord Chem. Rev. 2011, 255, 1460.

[9] (a) Kember, M. R.; Knight, P. D.; Reung, P. T. R.; Williams, C. K. Angew. Chem. Int. Ed. 2009, 48, 931. (b) Winkler, M.; Romain, C.; Meier, M. A. R.; Williams, C. K. Green Chem. 2015, 17, 300. (c) Romain, C.; Zhu, Y Dingwall, P; Paul, S; Rzepa, H. S.; Buchard, A.; Williams, C. K. J. Am Chem. Soc. 2016, 138, 4120. (d) Buchard, A.; Jutz, F; Kember, M. R. White, A. J. P.; Rzepa, H. S.; Williams, C. K. Macromolecules 2012, 45 6781. (d) Kember, M. R.; Williams, C. K. J. Am. Chem. Soc. 2012, 134, 15676.

[10] For some relevant examples where bimetallic catalysis plays a key role in polycarbonate formation process: (a) K. Nakano, S. Hashimoto, K Nozaki, Chem. Sci. 2010, 1, 369; b) S. Klaus, M. W. Lehenmeier, E. Herdtweck, P. Deglmann, A. K. Ott, B. Rieger, J. Am. Chem. Soc. 2011 133,13151 ; c) Y. Liu, W.-M. Ren, C. Liu, S. Fu, M. Wang, K.-K. He, R.R. Li, R. Zhang, X.-B. Lu, Macromolecules 2014, 47, 7775; d) Vagin, S. I.; Reichardt, R.; Klaus, S.; Rieger, B. J. Am. Chem. Soc. 2010, 132, 14367.

[11] (a) Auriemma, F.; De Rosa, C.; Di Caprio, M. R.; Di Girolamo, R.; Coates, G. W. Macromolecules 2015, 48, 2534. (b) Carrodeguas, L. P.; González-Fabra, J.; Castro-Gómez, F.; Bo, C.; Kleij, A. W. Chem. Eur. J. 2015, 21, 6115. (c) Auriemma, F.; De Rosa, C.; Di Caprio, M. R.; Di Girolamo, R.; Ellis, W. C.; Coates, G. W. Angew. Chem. Int. Ed. 2015 54, 1215. (d) Byrne, C. M.; Allen, S. D.; Lobkovsky, E. B.; Coates, G. W J. Am. Chem. Soc. 2004, 126, 11404. For other relevant contributions: (e) Hauenstein, O.; Reiter, M.; Agarwal, S.; Rieger, B. Greiner, A. 2016, 18, 760. (f) C. Li, R. J. Sablong, C. E. Koning, Angew. Chem. Int. Ed. 2016, 55, 11572
[12] For a small selection: Al-catalysis: (a) Aida, T.; Ishikawa, M.; Inoue, S Macromolecules, 1986, 19, 8; (b) C. Chatterjee, M. H. Chisholm, Inorg Chem. 2011, 50 , 4481; Co-catalysis: (c) Xia, W.; Salmeia, K. A.; Vagin, S. I.; Rieger, B. Chem. Eur. J. 2015, 21, 4384. Cr-catalysis: (d) Darensbourg, D. J.; Chung, W.; Yeung, A. D.; Luna, M. Macromolecules 2015, 48, 1679. Fe-catalysis: (e) Taherimehr, M.; Al-Amsyar, S. M. Whiteoak, C. J.; Kleij, A. W.; Pescarmona, P. P. Green Chem. 2013, 15, 3083. Ti/Zr/Ge/Sn-catalysis: (f) Nakano, K.; Kobayashi, K.; Nozaki, K. J. Am. Chem. Soc. 2011, 133, 10720. Yb-catalysis: (g) Decortes, A.; Haak, R. M.; Martín, C.; Belmonte, M. M.; Martin, E.; Benet-Buchholz, J.; Kleij, A. W. Macromolecules 2015, 48, 8197. (h) Hua, Y.; Yang, X.; Liu, M. Song, X.; Wang, M.; Chang, J. Macromolecules 2015, 48, 1651.

[13] a) C. J. Whiteoak, B. Gjoka, E. Martin, M. Martínez Belmonte, E. C. Escudero-Adán, C. Zonta, G. Licini, A. W. Kleij, Inorg. Chem. 2012, 51 10639-10649; b) C. J. Whiteoak, E. Martin, M. Martínez Belmonte, J. Benet-Buchholz, A. W. Kleij, Adv. Synth. Catal. 2012, 354, 469-476.

[14] Gaussian 09, Revision D.01, Frisch, M. J.; Trucks, G. W.; Schlegel, H. B.; Scuseria, G. E.; Robb, M. A.; Cheeseman, J. R.; Scalmani, G.; Barone, V.; Mennucci, B.; Petersson, G. A.; Nakatsuji, H.; Caricato, M.; Li, X.; Hratchian, H. P.; Izmaylov, A. F.; Bloino, J.; Zheng, G.; Sonnenberg, J. L.; Hada, M.; Ehara, M.; Toyota, K.; Fukuda, R. Hasegawa, J.; Ishida, M.; Nakajima, T.; Honda, Y.; Kitao, O.; Nakai, H.; Vreven, T.; Montgomery, J. A., Jr.; Peralta, J. E.; Ogliaro, F.; Bearpark, M.; Heyd, J. J.; Brothers, E.; Kudin, K. N.; Staroverov, V. N.; Kobayashi, R.; Normand, J.; Raghavachari, K.; Rendell, A.; Burant, J. C.; Iyengar, S. S.; Tomasi, J.; Cossi, M.; Rega, N.; Millam, M. J.; Klene, M.; Knox, J. E.; Cross, J. B.; Bakken, V.; Adamo, C.; Jaramillo, J.; Gomperts, R.; Stratmann, R. E.; Yazyev, O.; Austin, A. J.; Cammi, R.; Pomelli, C.; Ochterski, J. W.; Martin, R. L.; Morokuma, K.; Zakrzewski, V. G.; Voth, G. A.; Salvador, P.; Dannenberg, J. J.; Dapprich, S.; Daniels, A. D.; Farkas, Ö.; Foresman, J. B.; Ortiz, J. V.; Cioslowski, J.; Fox, D. J. Gaussian, Inc., Wallingford CT, 2013.

[15] (a) Becke, A. D. J. Chem. Phys.1997, 107, 8554. (b)Schmider, H. L.; Becke, A. D.J. Chem. Phys.1998, 108, 9624. (c)Grimme, S.; Ehrlich, S.; Goerick, L. J. Comp. Chem. 2011, 32, 1456.

[16] (a) Krishnan, R.; Binkley, J. S.; Seeger, R.; Pople, J. A. J. Chem. Phys 1980, 72, 650, (b) McLean, A. D.; Chandler, G. S. J. Chem. Phys.1980 72,5639

[17] Hay, P. J.; Wadt, W. R. J. Chem. Phys. 1985, 82, 270.

[18] CRC Handbook of Chemistry and Physics, Lide, D.R. (ed), 84th Ed. CRC Press LLC, Florida 2003.

[19] Álvarez-Moreno, M.; de Graaf, C.; Lopez, N.; Maseras, F.; Poblet, J.M.; Bo, C. J. Chem. Inf. Model. 2015, 55, 95-103. 


\section{Entry for the Table of Contents}

\section{FULL PAPER}

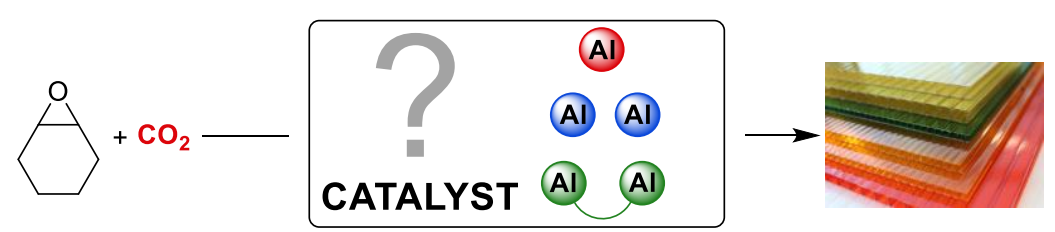

Two better than one: A computational study of several reaction mechanisms for $\mathrm{CO}_{2}$ /cyclohexene oxide copolymerization mediated by an [Al\{aminotri(phenolate) $\}] / \mathrm{NBu}_{4} \mathrm{X}$ binary catalyst suggest that a new non-covalent dimeric complex formed in situ in the reaction media is indeed the catalytic active species since it presents the most favourable free energy pathway.
Joan González-Fabra, Fernando CastroGómez, Arjan W. Kleij and Carles Bo*

$1-8$

Mechanistic Insights into the Carbon Dioxide-Cyclohexene Oxide Copolymerization reaction: Is one Metal Center enough? 